\title{
RESPONSABILIDADE SOCIAL: A PARTICIPAÇÃO DAS MULHERES NAS ORGANIZAÇÕES DE BLUMENAU (SC)
}

\author{
SOCIAL RESPONSIBILITY: THE PARTICIPATION OF WOMEN IN \\ ORGANIZATIONS BLUMENAU (SC)
}

\section{Marialva Tomio Dreher}

Fundação Universidade Regional de Blumenau (FURB)

\section{Renata dal Moro}

Universidade Regional de Blumenau (FURB)

\section{RESUMO}

Este estudo objetiva analisar a participação das mulheres na gestão da responsabilidade social (RS) das Organizações de Blumenau (SC). 0 método de pesquisa foi à qualitativa e as técnicas exploratórias e descritivas. A população foi de 21 gestoras de RS das organizações vinculadas ao Núcleo de Responsabilidade Social da Associação Comercial e Industrial de Blumenau (NÚCLEO RS/ACIB). Os resultados confirmam que o índice de 21 mulheres gestoras de RS é elevado considerando que há 24 organizações no Núcleo. 0 perfil demonstra que a maioria é casada e possui filhos, estes motivos não limitam as gestoras a ingressar no mercado de trabalho e a assumir uma gestão de RS, pelo contrário representa uma conquista profissional. Todavia, afirmam que devido ao acúmulo de atividades, doméstica e profissional, ocorrem exigências demasiadas pelo excesso de compromissos. Quanto à gestão da RS, observou-se que há uma identificação pessoal das gestoras com a temática.

Palavras-chave: Gênero. Mulher. Organizações. Responsabilidade social.

\begin{abstract}
This study analyzes women's participation in managing social responsibility (SR) of organizations in Blumenau (SC). The research method was qualitative and descriptive and exploratory techniques. The population was 21 RS managers of organizations linked to the Center for Social Responsibility of Commercial and Industrial Association of Blumenau (CORE RS / ACIB). The results confirm that the rate of 21 female managers of RS is high considering there are 24 organizations in the Core. The profile shows that the majority is married and has children, those reasons do not limit managers to enter the labor market and assume management of RS instead represents a professional achievement. However, they state that due to the accumulation of activities, domestic and professional, there are too many demands for excessive commitments. For the management of RS, it was observed that there is a personal identification with the subject of management.
\end{abstract}

Keywords: Gender. Women. Organizations. Social responsibility. 


\section{INTRODUÇÃO}

A discussão sobre Responsabilidade Social (RS) é bastante difundida, ora pelo seu apelo "empresarial" e mercantil, ora pelas cobranças da sociedade para um mundo mais humanizado e ecologicamente mais saudável. Devido a isso, muitas organizações de variadas áreas buscam se adequar a esta realidade, que exige esforços em conhecimento, tecnologia e recursos para ser implementada. Os esforços, muitas vezes, são decorrentes das motivações dos sujeitos em mudar o atual contexto da relação das organizações com a sociedade e o ambiente. 0 empenho dos sujeitos é visto como a parte mais significativa de um processo de RS, visto que isso depende do comprometimento pessoal e organizacional (DREHER, 2009).

Todavia, os obstáculos são muito complexos, pois envolvem desde a mudança de cultura, até a transformação de estrutura, entre outras modificações. Isto demanda um empenho coletivo, uma vez que um processo de RS não ocorre de maneira isolada, mas sim exige a participação e comprometimento de todos os stakeholders. Um exemplo disso é a preocupação com o bem estar dos colaboradores elemento básico da RS, que precisa atingir todo o ambiente da organização. Nesse sentido, um gestor de RS necessita de espaço e apoio para conseguir consolidar e legitimar suas ações. Diante deste desafio surge a seguinte questão que este estudo pretende responder: De que maneira ocorre a participação das mulheres na gestão dos processos de RS das organizações do município de Blumenau em Santa Catarina?

No contexto municipal há o Núcleo de Responsabilidade Social da Associação Comercial e Industrial de Blumenau (NÚCLEO RS/ACIB) que agrega as organizações que desenvolvem RS. No Núcleo é percebida uma expressiva maioria de mulheres na condução da RS independente do setor de atuação das organizações que representam. Compreender este cenário é o desafio deste estudo que pretende atender ao seguinte objetivo de pesquisa: analisar a participação das mulheres na gestão da RS das organizações de Blumenau (SC).

Salienta-se que a relevância desta investigação incidiu por incitar reflexões sobre a participação feminina na condução da RS numa região de históricos domínios masculinos na gestão das organizações locais. Como também, pela busca dos motivos organizacionais que sugerem as mulheres como principais condutoras dos processos de RS. Hipoteticamente, acredita-se que este fenômeno pode estar relacionado; à herança cultural verificada na historicidade da RS brasileira que envolvia, no passado, assistencialismo e filantropia geralmente conduzidos por mulheres. Estas questões movimentaram as organizações na relação com o campo social. Além disso, compreender melhor esta complexidade pode contribuir com novas condutas por parte das gestoras e suas organizações, numa maneira de criar novos espaços de articulação junto aos atuais movimentos da sociedade em prol do desenvolvimento da RS e da minimização das diferenças entre gêneros.

\section{RESPONSABILIDADE SOCIAL}

0 termo responsabilidade refere-se às atitudes que devem ser assumidas pelos sujeitos e organizações em qualquer situação de interação na sociedade. Neste caso, a complementação desta expressão com o termo "social", proposta pela responsabilidade social (RS), reforça essas atitudes ressaltando a necessidade, não apenas em assumir atos e falhas, mas de compromisso com o bem estar da sociedade em qualquer processo de decisão. Devido a esta complexidade, a RS precisa ser vista como um compromisso baseado na ética (DREHER, 2009). Conforme Chauí (2000) a ética é constituída pelas diferentes formações sociais e culturais, porém a origem cultural dos valores éticos, do senso moral e da consciência moral, não pode ser compreendida nem mensurada, afinal somos educados para eles e neles, como se fossem naturais ou fáticos, existentes em si e por si mesmos. Assim, para garantir a manutenção dos padrões morais através do tempo e sua continuidade de geração a geração, as sociedades tendem a naturalizá-los, a naturalização da existência moral esconde, portanto, o mais importante da ética: o fato de ela ser criação histórico-cultural. 0 campo ético é constituído pelos valores e pelas obrigações que formam o conteúdo das condutas morais, isto é, as virtudes. 
Observa-se assim que as implicações éticas afetam os sujeitos e suas organizações. Neste caso a RS também passa a ser preocupação nas empresas, vista como responsabilidade social empresarial (RSE), objeto deste estudo. A RSE já era inquietação em 1899, com Andrew Carnegie, um filantropista, norte americano do setor petrolífero, que escreveu "O Evangelho da Riqueza", afirmando que toda a riqueza pessoal, além do necessário, deveria constituir um fundo a ser administrado para o benefício da comunidade. Isto poderia seguir dois princípios, um da caridade e outro da custódia. No princípio da caridade, as pessoas mais afortunadas deveriam ajudar os menos afortunados. No princípio da custódia, apresentava a idéia de que os ricos guardavam o dinheiro da sociedade e deveriam usar este dinheiro em qualquer objetivo que a sociedade precisasse (CARNEGIE CORPORATION, 2009).

A partir do século XX, os princípios da caridade e da custódia eram muito bem aceitos nas empresas americanas, vistas como "poder é responsabilidade". (STONER; FREEMAN, 1985). Neste sentido, Bowen (1957), afirmava que a aceitação voluntária da RS pelos homens de negócios seria, ou poderia ser um meio prático para melhorar os problemas econômicos e atingir completamente as metas econômicas vividas. Carroll (1991) ressalta que a responsabilidade social refere-se às ações e decisões incorporadas aos vínculos empresariais. O Instituto Ethos (2009) relata que a RSE pode ser compreendida por uma gestão ética e transparente da empresa com todos os públicos de interesse. A ética é à base da responsabilidade social, expressa nos princípios e valores adotados pela organização. Não há RS sem ética nos negócios. Não adianta uma empresa pagar mal seus funcionários, ao mesmo tempo, desenvolver programas voltados a entidades sociais da comunidade. Essa postura não condiz com uma empresa que quer trilhar um caminho socialmente responsável.

Porém entre os anos de 1970 e 1980, a convergência de várias forças econômicas gerou muitas discussões, pois alguns estudiosos "sugeriam que o conceito de RS não indicava o envolvimento empresarial de magnitude apropriada, nem sugeria como uma empresa deveria avaliar suas responsabilidades sociais em relação as suas outras responsabilidades" (STONER; FREEMAN, 1985, p. 73). A evolução da RS passou por muitos momentos de reflexão, inclusive críticas, que afirmavam que era o governo, as igrejas e outras entidades não-governamentais que deveriam se responsabilizar com as demandas sociais, sugerindo que as empresas não assumissem esta função (RUFFEIL, 2009). 0 economista Milton Friedman (1988), por exemplo, num posicionamento crítico em relação à RS argumentava que o papel do governo é o de determinar, arbitrar e pôr em vigor as regras do jogo e que os assuntos sociais não competem ao setor privado, e este problema pode ser resolvido com o funcionamento do sistema de livre comércio. Além disso, só há uma RS para as empresas utilizar os recursos em atividades destinadas a aumentar os lucros dos acionistas.

No entanto, vários foram os movimentos em prol do processo de RS, no Brasil, os indícios de que uma mudança empresarial estaria acontecendo foram percebidos na década de 60 , quando novas idéias começaram a ser discutidas, foi criada a Associação dos Dirigentes Cristãos de Empresas (ADCE) uma das pioneiras na discussão da função social das empresas (RUFFEIL, 2009). Já em 1974, a associação ADCE publicou outro importante documento, "O Decálogo do Empresário", sendo a primeira proposta clara de ligar a gestão empresarial com a RS (CAPELLIN; GIFFONI, 2007). Na década de 80, as empresas passaram a adotar a RS como uma estratégia empresarial.

De acordo com Assis e Belem (2009) na década de 90, as empresas brasileiras passavam por reestruturações internas visando aumentar sua competitividade no mercado internacional, e a entrada da RS nas empresas surgiu como uma proposta para racionalizar custos, administrar riscos e valorizar a reputação das empresas. Deste modo, Cappellin e Giffoni (2007) ressalvam que a segunda fase da estruturação da RS no Brasil ocorreu através da regulamentação dos direitos humanos e com a expansão das ações sociais empresariais para fora das empresas, ou seja, para a sociedade.

Carroll (1991) apresenta a abordagem conceitual da RSE sendo reconhecida pelas ações e decisões incorporadas aos vínculos empresariais. Em sua visão empresarial e numa tentativa de ressaltar as obrigações das organizações enquanto papel produtivo na sociedade apresenta a RS através de quatro dimensões, sendo elas: as responsabilidades econômicas, jurídicas ou legais, éticas e filantrópicas. Na responsabilidade econômica, as organizações devem obter o lucro. Já na responsabilidade jurídica ou 
legal espera que as empresas cumpram as leis e regulamentos promulgados pelos governos de acordo com a esfera na qual devem operar. As responsabilidades éticas envolvem os padrões, normas, expectativas que refletem uma preocupação de que os stakeholders consideram justo, e a última responsabilidade, a filantrópica engloba as ações corporativas que são à expectativa da sociedade de que as empresas sejam bons cidadãos corporativos. Neste sentido Alves (2003) afirma que a empresa, enquanto organização técnico-social exerce inúmeras funções relevantes para a sociedade. Ao realizar suas tarefas sociais, entra em contato com o ambiente externo, no qual está inserida, e interage com ele, sendo adequado à empresa ser reconhecida como parte de um sistema social aberto e dinâmico. Em outras palavras, cada empresa é uma organização técnico-social dotada de características específicas, com objetivos próprios e que compreende dinâmicas entre as variáveis de dentro do seu sistema organizacional, bem como dinâmicas entre essas variáveis e as do ambiente externo e viceversa.

De acordo com Ashley (2003) a RS é um compromisso que uma organização deve ter com a sociedade, expresso por meio de atos e atitudes que afetam positivamente na qualidade de vida de uma sociedade. Já Cabral (2005) se refere a RS como sendo um conceito ambivalente e contraditório, pois de um lado encontram-se os diversos grupos para o enfrentamento da desigualdade social. Por outro, evidencia o risco de transferência entre a responsabilidade dos indivíduos e do Estado. Portanto, a RS apresenta duas faces a integradora e a desintegradora. Na visão integradora da RS, sugere-se o ajuste das ações de RS, com visão de médio e longo prazo, contra as diferentes formas de exclusão social, e de acordo com os valores culturais e éticos.

Para contribuir com o processo de evolução e implementação da RSE nas organizações, algumas instituições nacionais e internacionais desenvolveram normas e instrumentos que norteiam as organizações no processo de implementação e estruturação da RS, a saber: SA 8000 (Social Accountability International), a NBR 16001 (Norma Nacional de RS) e a ISO 26000 (International Organization for Standardization) como normas não-governamentais que deveriam se responsabilizar com as demandas sociais, sugerindo que as empresas não assumissem esta função (RUFFEIL, 2009). 0 economista Milton Friedman (1988), por exemplo, num posicionamento crítico em relação à RS argumentava que o papel técnicas. Os Indicadores Ethos de RS, Balanço Social Instituto Brasileiro de Análises Sociais e Econômicas (IBASE), o GRI (Global Reporting Iniciative) e o Índice de Sustentabilidade Empresarial da Bolsa de Valores de São Paulo (ISE) como instrumentos de apoio. Para Dreher (2009), estes instrumentos são os mais adotados no Brasil, no entanto existem outros que são utilizados para atender demandas específicas e motivados por diversas áreas em alguns municípios, por exemplo, o "hóspede da natureza" da área de hotelaria e a agenda 21, que também se adequaram às questões sociais do desenvolvimento sustentável.

\section{A PARTICIPAÇÃO DAS MULHERES NA CONDUÇÃO DA RESPONSABILIDADE SOCIAL}

A introdução da responsabilidade social (RS) nas organizações é bastante recente, e a cada dia se busca implementá-la e também aprimorá-la, afinal as ações desempenhadas com a RS se voltam para o bem-estar da organização e da sociedade. Neste contexto, pode-se destacar a participação de muitos gestores e gestoras que buscam a cada dia adaptar-se a este desafio. Todavia, observa-se que entre muitos desafios vistos na sociedade, é possível notar a diferença que ainda prevalece entre homens e mulheres. Neste contexto, Eccel e Grisci (2009) ressaltam que no Brasil, o foco das pesquisas em Administração sobre gênero no trabalho costuma recair sobre as mulheres. Desenvolvendo trabalhos sob uma perspectiva de inserção da mulher no mercado de trabalho. Por outro lado, os homens costumam ser vistos como bloco homogêneo e a masculinidade permanece como um atributo naturalizado, fazendo com que o masculino-feminino se neutralize, impossibilitando de se perceber as diferenças entre os homens e suas vivências masculinas e as mulheres.

Com base nestes conceitos, Scott (2007) afirma que o uso do termo "gênero" visa indicar a cultura e a seriedade de um trabalho, pois "gênero" tem uma conotação objetiva e neutra. Além de gênero ser igualmente utilizado para designar as relações sociais entre ambos os sexos, afinal homens e mulheres dividem o mesmo espaço, e não é correto falar de um sem falar do outro, este termo afirma ainda que 
as relações entre os sexos são sociais, mas não apresenta nenhum conceito exato a respeito de como essas relações são construídas, como funcionam ou como mudam de comportamento. Além de apresentar duas propostas teóricas para tentar explicar o conceito de gênero e de como as relações entre os sexos se estrutura na história. Uma proposta é de que gênero é um elemento constitutivo de relações sociais baseado nas diferenças entre ambos os sexos, fazendo com que se percebam as diferenças de gênero nas relações sociais e institucionais; e o outro aspecto é a apresentação do gênero como forma de poder, pois as diferenças sexuais entre homens e mulheres é um meio eficaz que remete ao poder, afinal homens sempre estiveram inseridos no mercado de trabalho ao longo da história.

\begin{abstract}
O termo gênero circula com uma acepção específica e com certa intencionalidade política. 0 respeito à alteridade feminina é condição para que se entenda o verdadeiro significado da igualdade mulher-homem. Não é uma igualdade que se concretiza na eterna repetição dos mesmos modelos de masculino e feminino, não é uma igualdade que anula os sexos, ou que considera o masculino como protótipo do humano. Ao contrário reconhece a igualdade como indispensável para possibilitar a reciprocidade entre mulheres e homens (BRANDÃO; BINGEMER, 1994, p. 16).
\end{abstract}

Neste contexto, este estudo procura situar à problemática de gênero numa abordagem que discute a participação das mulheres conectadas aos estudos organizacionais. Segundo Calas e Smircich (1998) os estudos organizacionais envolvem temas desde a preocupação com a mulher (seu acesso à organização e seu desempenho), passando pela relação entre gênero e organização (a noção de práticas organizacionais influenciadas por relações de gênero), até a consideração da estabilidade das categorias: gênero, feminilidade, masculinidade e organização. Cada linha de pensamento oferece formas alternativas para o enfoque da desigualdade de gênero. Deste modo, termo feminilidade já vem a bastante tempo sendo discutido, mas ainda apresenta um tema abstrato, pois se procura falar de mulher concreta, que sempre esteve ligada a luta pela cidadania, pela escuta da voz feminina, pela busca do espaço para expor seu pensamento ao mundo, pela sua visibilização na esfera doméstica e pública (BRANDÃO; BINGEMER, 1994).

Sardenberg e Costa (1994) afirmam que o reconhecimento e a consciência de gênero entre as mulheres, antigamente, foi identificada primeiramente na Europa, mais precisamente na França e na Inglaterra, devido às transformações que estavam ocorrendo, com a introdução do sistema capitalista na economia. Esta transformação carregava consigo as mudanças que poderiam ocorrer nas organizações familiares e sobre o que realmente é o "indivíduo". Porém, os homens conceituaram uma declaração só para eles, conhecida como "Declaração dos direitos do homem", enquanto isso a mulher carregava os códigos patriarcais inscritos em Paris, alegando que a mulher deveria ter liberdade só entre os muros domésticos, e os direitos que poderia ter era só de boa filha, esposa e mãe. Para Perrot (1998) a mulher foi criada para a família e para as coisas domésticas assim mãe e dona de casa era a sua vocação, sendo benéfica para toda a sociedade.

Deste modo, nos últimos 40 anos o movimento pela "libertação das mulheres" obteve consideráveis ganhos sociais, políticos e econômicos melhorando a situação de muitas mulheres. Apesar desses avanços, a segregação sexual nos empregos e organizações persiste como fenômeno mundial, assim como a desigualdade remuneratória entre os sexos. (ADLER; IZRAELI, 1988 apud CALAS; SMIRCICH, 1998). Observa-se que apesar da diversidade, a maior parte das teorias feministas tem alguns pressupostos comuns, notadamente o reconhecimento da dominação masculina, os arranjos sociais e o desejo de mudança nessa forma de dominação. Uma distinção conceitual central entre as teorias é o entendimento do gênero, pois as primeiras teorias do feminismo liberal preocupavam-se com as desigualdades entre os sexos, isto é, entre duas categorias de pessoas o "masculino e o feminino" identificadas por suas características biológicas, na sua evolução a teoria extinguiu entre "sexo" biologicamente definido e "gênero" sociologicamente construída, um produto da socialização e vivência (CALAS; SMIRCICH, 1998).

Diante disso, ainda conforme Calas e Smircich (1998) a literatura acompanhou os movimentos feministas e foram criadas várias teorias com diversas abordagens para o processo de introdução da 
mulher no mercado de trabalho, dentre elas: liberal (evidencia a desigualdade econômica, usando um símbolo que carrega forte credibilidade social e acadêmica), radical (oferece "o aumento da consciência" como uma forma única de pesquisa e prática organizacional), psicanalista (promove modificações em relações de gênero e em práticas educativas, rumo à redução da desigualdade social de gênero), marxista (baseada na crítica marxista da sociedade capitalista), socialista (foco nas relações de gênero e sistema de sexo-gênero), pós-estruturalista (permite a articulação da "política do conhecimento" como uma forma de relações de poder) e terceiro mundista (problematiza o conceito de gênero, e abre possibilidades mais complexas entre homens e mulheres).

Deste modo, Fournier e Smith (2006) ressaltam que existe um formato cada vez mais familiar nos estudos de gênero, que remove a sua inspiração de pós-estruturalismo visando ser "reflexiva" e se envolvendo com a produção de identidades masculinas e femininas. Esta visão muda o foco de análise dos homens e mulheres no sentido de masculinidades e feminilidades, com a intenção de rejeitar o dualismo simplista e essencialista que têm assolado a análise de gênero, nos convidando a explorar a produção de identidades de gênero. Observa-se que apesar da diversidade, a maior parte das teorias feministas tem alguns pressupostos comuns, notadamente o reconhecimento da dominação masculina, os arranjos sociais e o desejo de mudança nessa forma de dominação. Uma distinção conceitual central entre as teorias é o entendimento do gênero, pois as primeiras teorias do feminismo liberal preocupavam-se com as desigualdades entre os sexos, isto é, entre duas categorias de pessoas o "masculino e o feminino" identificadas por suas características biológicas, na sua evolução a teoria extinguiu entre "sexo" biologicamente definido e "gênero" sociologicamente construída, um produto da socialização e vivência. Sendo assim, na abordagem pós- estruturalista e terceiro mundista problematiza-se a noção de "experiência" questionando a estabilidade de sexo e gênero como categorias analíticas, e, lembrando que a subjetividade é construída lingüística, histórica e politicamente sendo, portanto, flexível e múltipla. Por isso, "gênero" é um termo ainda em construção (CALAS; SMIRCICH, 1998).

A diferença biológica entre os sexos, isto é, entre o corpo masculino e o corpo feminino, e, especificamente, a diferença anatômica entre os órgãos sexuais, pode assim ser vista como justificativa natural da diferença socialmente construída entre gêneros e, principalmente, da divisão social do trabalho. (BOURDIEU, 1999, p. 20)

No Brasil, o pensamento feminista surgiu no século passado, desde então vem assumindo várias formas de luta, diversas bandeiras e diferentes facetas. Em 1927, surgiu o "Manifesto feminino", que assegurava a liberdade para as mulheres. Em 1934, houve a eleição da primeira mulher como deputada suplente na Câmara Federal, em 1937, ela apresenta o projeto "Estatuto da mulher", que garantia a licença maternidade de três meses para as mulheres, incluindo o aborto natural, que só foi garantido na Constituição de 1988. Na ditadura militar o movimento feminista foi interrompido, ressurgindo no Rio de Janeiro, em 1975, reunindo mulheres de vários lugares do país para discutirem a condição feminina na sociedade. A elaboração da Constituição Federal de 1989 auxiliou as mulheres em suas lutas, pois a mulher passou a ser reconhecida como seres responsáveis e socialmente produtivos. Salienta-se ainda que a luta pela conquista de espaço da mulher continua até os dias de hoje (SARDENBERG; COSTA, 1994).

A despeito da volumosa literatura e de sua aparente variedade os estudos falham em reconhecer as implicações políticas da questão de gênero. No entanto, no caso brasileiro, Barsted (1994), afirma que a partir da década de 90 , foi necessário questionar se as discussões e movimentos de igualdade entre os sexos foi alcançada ou se estava sendo inserida nos projetos mais modernos. Pois o que era escondido dentro de casa ou em lugares privados, veio à tona e foi revelado em público, mas foi desta forma que o Estado, as instituições, os políticos e os sindicatos conseguiram enxergar os problemas que acometiam a sociedade.

Sabe-se, portanto, que a mudança efetiva e profunda nas relações entre os sexos é um processo lento, difícil e cheio de contradições. A mulher, depois de anos de luta, consegue se inserir no mercado, mas sabe que não pode deixar de fazer as suas tarefas no âmbito privado, surgindo assim a "dupla jornada", 
que é a união do trabalho público com o privado, que não se constitui aos homens, pois os mesmos não têm tarefas privadas. Apesar de a mulher estar inserida no trabalho público ainda é na sua grande maioria discriminada e desvalorizada, e este olhar para as transformações das relações dos homens e das mulheres pode mostrar uma relação que abre espaços para problemas que afetam a sociedade, as instituições e o próprio desenvolvimento, mas que se bem tratados podem abrir uma dimensão verdadeiramente humanista ou igualitária (BARSTED, 1994). Deste modo, observa-se que a "sociedade sempre foi masculina; o poder político sempre esteve nas mãos dos homens". (BEAUVOIR, 1980, p.54). Bourdieu (1999) ressalta que a ordem social funciona como uma imensa máquina simbólica que tende a ratificar a dominação masculina sobre a qual se alicerça a divisão social do trabalho, distribuição bastante estrita das atividades atribuídas a cada um dos dois sexos, determinado uma estrutura para homens e mulheres, em que reserva-se para os homens o espaço de assembléias e os mercados, e a casa, reservada as mulheres, ou até mesmo no interior da mesma, o salão fica com os homens e as mulheres com a cozinha. Calas e Smircich (1998) apresentam nas publicações recentes e populares sobre negócios, é possível notar que não somente as desigualdades estão crescendo, mas também se tornaram natural por um discurso que reafirma que estas são uma condição normal para sociedades ao redor do mundo. Sob essa ótica, ate as abordagens do feminismo liberal sobre justiça de gênero parecem radicais. Devido a isso, é necessário que se continue a questionar a discriminação e a opressão causadas pelas formas contemporâneas do capitalismo, freqüentemente com amplas implicações em atitudes organizacionais.

Neste sentido, Sardenberg e Costa (1994) afirmam que a subordinação da mulher é um acontecimento milenar que percorre diversas partes do mundo e também diferentes culturas. Desde modo, o surgimento da consciência crítica "feminista" acerca da libertação da mulher é um fenômeno bem recente, com a expansão do capitalismo e o eclodir da modernidade, delineando-se nos últimos tempos com maior ênfase. Além disso, nas atuais sociedades, onde prevalece à hierarquia racial e étnica, é certo que a situação de dominação que a mulher é exposta se manifesta em diferentes níveis e intensidades de acordo com a cultura em que ela esta inserida, o que acaba interferindo na identidade pessoal da mulher, pois cada uma é única e tem suas próprias características.

Em recente pesquisa realizada no Brasil por Irigaray e Vergara (2009) foi observado que o campo revelou que: a) as mulheres são, de fato, submetidas a práticas discriminatórias no ambiente de trabalho, as quais, não raramente, se escondem sob a máscara de humor e informalidade; b) apesar de atitudes e comentários machistas, os homens não se percebem como tal; c) a cultura nacional brasileira prevalece sobre as culturas organizacionais; d) gênero não pode ser tratado como uma categoria sólida, uma vez que as questões estéticas, etnia, classe social e orientação sexual acentuam a discriminação e, finalmente, e) ao contrário do que acontece com os negros, feios e homossexuais, os que vêem a discriminação serem atenuada por uma posição social ou hierárquica mais favorecida, o mesmo não acontece com as mulheres. Do mesmo modo, as organizações apesar de seus discursos neutros e politicamente corretos, são cúmplices de práticas cotidianas que submetem as mulheres a uma subordinação erotizada também no ambiente de trabalho. Elas passam a ser consideradas oeixo de verticalização das relações entre os gêneros.

Acredita-se que esta realidade varia de acordo com a cultura e o espaço de liberdade e ética das organizações, como também, de sua própria constituição enquanto ambiente de produção e missão. As dificuldades de relacionamento entre gêneros precisam ser sempre avaliadas conforme cada caso e, em especial na sua historicidade. Não é válido, atualmente, argumentar em favor da generalização das problemáticas desse fenômeno (DREHER, 2009).

\section{MATERIAL E MÉTODOS}

Com relação às variáveis que determinam o objeto de estudo, esta pesquisa pode ser classificada como Exploratória, permitindo ao pesquisador aumentar sua experiência em torno de determinado problema e sua descrição e, que habitualmente realizam os pesquisadores sociais preocupados com a atuação prática (GIL, 1999). 
A população desta pesquisa foi composta pelas mulheres gestoras de RS das organizações de Blumenau (SC) que desenvolvem programas de RS no município. Ressalta-se que esta pesquisa teve como base as organizações vinculadas ao Núcleo RS/ACIB, no qual há 24 organizações cadastradas, destas 21 são representadas por mulheres, contudo somente 16 gestoras responderam a entrevista, 05 não quiseram participar alegando falta de tempo para tal. 0 procedimento de coleta dos dados utilizou a aplicação de entrevista semi-estruturada para identificar a opinião das mulheres sobre sua participação na gestão da RS. Após a coleta os dados foram organizados para a análise e interpretação, constituindo-se ambas o núcleo central desta pesquisa. A análise e interpretação dos dados foi realizada numa abordagem qualitativa e de duas formas. Primeiramente foram adotados os passos, muito parecidos com a pesquisa clássica, sugeridos por Gil (1999) o estabelecimento de categorias e tabulação para análise das questões fechadas e interpretação dos dados das questões abertas mais subjetivas. No segundo momento, privilegou-se a discussão em torno do que foi obtido, ou seja, uma leitura acerca da realidade estudada no seu aspecto amplo das respostas e as percepções observadas. Os índices apresentados formaram um apoio a esta análise, sem valorizar a questão puramente numérica dos dados. No final deste processo estão indicados os resultados finais mais significativos.

\section{O CONTEXTO DA PARTICIPAÇAO DAS MULHERES NA RS NAS ORGANIZAÇÕES DO NÚCLEO DE RS/ACIB}

A partir da perspectiva de construir um caminho ordenado para o desenvolvimento da RS entre as empresas do município de Blumenau, foi criado em 2005 o Núcleo de Responsabilidade Social da Associação Comercial e Industrial de Blumenau (NÚCLEO RS/ACIB). Este movimento tem como principal objetivo estimular o desenvolvimento da RS de modo coletivo entre as organizações, com foco no desenvolvimento sustentável do município. As iniciativas visam aprofundar os conceitos de RS corporativa, através de palestras e treinamentos abertos e seminários, além de identificar qual é a maior demanda da realidade de Blumenau para promover programas de voluntariado nas áreas de educação, saúde, meio ambiente e segurança. O Núcleo conta atualmente com a participação de 24 organizações cadastradas, destas, 21 organizações são representadas por mulheres (Quadro 1), 16 delas formam a população deste estudo. Como a maioria é gestora percebe-se que a obtenção de cargo de gestão é considerada um progresso nas dificuldades do passado. 
Quadro 1: Organizações pesquisadas

\begin{tabular}{|c|c|c|c|c|c|}
\hline ORGANIZAÇŌES & FUNDAÇÃO & PORTE & $\begin{array}{c}\text { SETOR/ } \\
\text { INTERESSE }\end{array}$ & $\begin{array}{c}\text { SEGMENTO } \\
\text { DE ATUAÇÃO }\end{array}$ & $\begin{array}{l}\text { PROGRAMAS/ } \\
\text { PÚBLICOS }\end{array}$ \\
\hline Organização 1 & 1850 & Médio & Privado & Gráfico & Interno \\
\hline Organização 2 & 1880 & Grande & Privado & Têxtil & Interno/ externo \\
\hline Organização 3 & 1882 & Grande & Privado & Têxtil & Interno \\
\hline Organização 4 & 1922 & Grande & Privado & Têxtil & Interno/ externo \\
\hline Organização 5 & 1924 & Grande & Privado & Fundição de aço & Interno/ externo \\
\hline Organização 6 & 1926 & Grande & Privada & Têxtil & Interna \\
\hline Organização 7 & 1940 & Grande & Privado & Têxtil & Interno/ externo \\
\hline Organização 8 & 1942 & Grande & Terceiro setor & $\begin{array}{c}\text { Educaçāo } \\
\text { profissional }\end{array}$ & Interna/ externa \\
\hline Organização 9 & 1953 & Media & Publico & Educação & Interno/ externo \\
\hline Organização 10 & 1961 & Grande & Privado & Elétricos & Intento/ externo \\
\hline Organização 11 & 1971 & Grande & Terceiro setor & Saúde & Interna/ externa \\
\hline Organizaçāo 12 & 1991 & Pequeno & Privado & Chocolates & Interno \\
\hline Organização 13 & 1996 & Pequena & Privado & $\begin{array}{c}\text { Educação } \\
\text { profissional }\end{array}$ & Externo \\
\hline Organização 14 & 1996 & Pequeno & Privado & Consultoria & Interna \\
\hline Organização 15 & 1996 & Pequena & Privado & Metalúrgica & Interna \\
\hline Organização 16 & 2002 & Grande & Terceiro setor & $\begin{array}{l}\text { Educação } \\
\text { profissional }\end{array}$ & Interna/ externa \\
\hline Organização 17 & 2005 & Pequena & Público & $\begin{array}{l}\text { Assistência } \\
\text { social }\end{array}$ & Externo \\
\hline Organização 18 & 2005 & Pequena & Privado & Consultoria & Interno/externo \\
\hline Organização 19 & 2007 & Pequeno & Privado & $\begin{array}{c}\text { Educaçāo } \\
\text { profissional }\end{array}$ & Interno \\
\hline Organização 20 & & Grande & Privado & Têxtil & Interno/ externo \\
\hline Organização 21 & & Pequena & Terceiro setor & $\begin{array}{l}\text { Educação, } \\
\text { ambiente/cultura }\end{array}$ & Externo \\
\hline
\end{tabular}

Fonte: Dados da pesquisa

Neste contexto, com relação às conquistas e os limites de poder e decisão no processo de gestão da RS nestas organizações, buscou-se investigar por meio de entrevista semi-estruturada a percepção das mulheres na atuação com RS. Diante disso, a Tabela 1 evidencia que em relação ao perfil das gestoras que a maioria $(62,50 \%)$ das entrevistadas é casada, indicando que o casamento não interfere na sua decisão de inserção no mercado de trabalho. Outras $25 \%$ das entrevistadas são solteiras. Uma das entrevistadas $(6,25 \%)$ é divorciada, e uma $(6,25 \%)$ é viúva. Esta percentagem evidencia a luta por um espaço no mercado de trabalho por estas mulheres independentes, que adiam ou que não desejam uma relação de casamento em detrimento da ascensão profissional.

Tabela 1: Estado Civil

\begin{tabular}{l|c|c}
\hline \multicolumn{1}{c|}{ ESTADO CIVIL } & FREQÜENCIA & $\%$ \\
\hline Casada & 10 & 62,50 \\
\hline Solteira & 4 & 25,00 \\
\hline Divorciada & 1 & 6,25 \\
\hline Viúva & 1 & 6,25 \\
\hline TOTAL & $\mathbf{1 6}$ & $\mathbf{1 0 0 , 0 0}$ \\
\hline
\end{tabular}

Fonte: Dados da pesquisa

Neste sentido, Bourdieu (1999) afirma que a mudança ocorrida no fato de que a dominação masculina não se impõe, é vista no adiamento da idade do casamento e no aumento do acesso das mulheres a instrução, conseqüentemente buscando a independência econômica e a transformação das estruturas familiares (o divórcio, por exemplo). Observou-se ainda que 50\% das entrevistadas têm filhos, comprovando que as mesmas assumem uma dupla jornada de trabalho e conseqüentemente excessos de compromissos como mães e profissionais, evidenciando que apesar de inseridas no mercado de trabalho, não deixaram de realizar seu principal papel natural, o de ser mãe. Todavia, 43,75\% 
aguardam esta função mesmo sendo casadas, dentre estas apenas uma é solteira. Além disso, todas são jovens com menos de 30 anos, em estágio de formação familiar. Quanto à quantidade de filhos, indicada na parte aberta desta pergunta, a resposta ficou em $50 \%$ com 1 filho; 37,5\% com 2 filhos e $12,5 \%$ com 3 filhos. Isto representa que a pequena quantidade de filhos segue a tendência demográfica vista nos últimos anos devido à inserção das mães (mulheres) no mercado de trabalho.

Em relação à idade das entrevistadas observa-se que 43,75\% têm idade entre 36 a 45 anos; 31,25\% têm idade de 26 a 35 anos; 12,5\% têm idade entre 46 e 55 anos; 6,25\% têm idade até 25 anos e, por fim, 6,25\% têm mais de 56 anos. A idade das gestoras demonstra que o interesse pelo desenvolvimento da RS esta diretamente ligada ao sentimento de afetividade e de cuidado, ligados ao perfil histórico da mulher, alem de que a maioria encontra-se numa etapa de formação familiar. Este fato também pode ser evidenciado nas discussões das gestoras para dar continuidade ao processo de desenvolvimento da RS e também nos projetos desenvolvidos pelas organizações em que atuam, pois a maioria das ações desenvolvidas é voltada para a família do colaborador, para as crianças e jovens / adolescentes da sociedade.

Sobre a formação acadêmica verificou-se que 31,25\% possuem formação acadêmica em serviço social, uma representatividade que justifica os anseios dessa profissão, além de evidenciar um aspecto positivo quanto ao foco centrado nas demandas sociais dessas profissionais. Isso confirma que as organizações já estão começando a preocupar-se com a contratação de especialistas para gerenciar as questões sociais. Porém, este fato não ocorre em todos os casos, sendo que em igual porcentagem $(12,50 \%)$ são formadas em administração, comunicação social e psicologia e, ainda, novamente em igual percentual $(6,25 \%)$ está à economia, pedagogia, mestrado em desenvolvimento regional e outros. Embora a discussão social não seja foco dessas formações, também aborda esta questão, pois dialogam sobre estes temas nas áreas das Humanas e Ciências Sociais Aplicadas, favorecendo tanto a gestão quanto o conhecimento parcial dessa temática.

Quanto à formação complementar na área social, verificou-se que $50 \%$ das gestoras possuem alguma formação na área social, confirmando que as gestoras têm informações acerca do processo de RS; entretanto $50 \%$ não possuem formação complementar na área social, mas apresentam interesse pessoal em desenvolver e discutir as ações de RS, esse interesse pode ser observado na participação das mulheres nas reuniões do Núcleo de RS/ACIB, pois interagem com as outras entrevistadas que tem formação na área social, compartilhando informações e conhecimento na condução do processo de RS. Na parte aberta desta questão, com relação às entrevistadas que possuem formação na área social, observa-se que $50 \%$ apresentam formação complementar através de cursos, seminários e especializações voltados para a RS; as outras 50\% das respostas apresentaram formação na área social: serviço social, auditoria em RSE, mestrado em desenvolvimento regional e mestrado em administração com linha de pesquisa em RS e terceiro setor, sendo assim as entrevistadas possuem muitas informações acerca do processo da RS.

Entretanto, percebe-se, que a maioria (68,75\%), antes da atual atuação, não possuía experiência anterior na área social, mesmo assim conquistaram uma representatividade junto ao Núcleo RS/ACIB que é uma construção coletiva recente. Nas organizações que trabalham atualmente vem desenvolvendo projetos e programas de RS ainda em estágio embrionário ou em desenvolvimento voltados ao âmbito interno junto aos colaboradores. Apenas, $31,25 \%$ das entrevistadas já possuíam experiência anterior na área social, pelo período médio de 6 anos, apresentando atualmente projetos e ações mais consistentes e mais abrangentes atingindo também o público externo, duas dessas já conduzem processos de RS com certificação no mercado, evidenciando que a inserção da mulher no mercado de trabalho traz benefícios para elas, para as organizações e para a sociedade, alem de demonstrarem que possuem capacidade de assumir duas jornadas simultaneamente: a de mãe e esposa e de gestora. Para complementar esta questão apesar da pouca experiência das gestoras com o processo de RS, devido ao pouco tempo em que desempenham atividades ligadas a este processo, já apresentam iniciativas, ainda em fase embrionária, de projetos e programas de RS nas organizações em que se inserem atualmente, pois a maioria $(62,5 \%)$ das gestoras atua com RS num período de 1 a 3 anos; outras 18,75\% afirmam desenvolverem a RS num período de 4 a 5 anos; $12,5 \%$ desenvolvem de 
6 a 10 anos e, 6,25\% não responderam a questão. Além disso, as entrevistadas trocam informações e experiências através do Núcleo de RS/ACIB, que auxilia na construção e desenvolvimento dessa atividade nas organizações do município.

Neste contexto, pode-se afirmar que a RS é uma atividade recente nas organizações nucleadas e estas ainda não se encontram estruturadas para tal. Deste modo, verificou-se ainda que as gestoras que desenvolvem a RS encontram-se alocadas em outros setores e departamentos, ocupando cargos distintos, além do desenvolvimento da RS, a saber: 4 são gerentes; 1 dirigente/proprietária; 1 assessora; 8 assistentes de gerência e 2 autônomas. Em nenhum dos casos existe uma gerência ou departamento específico de RS, apenas há vínculos a outros departamentos ou setores.

Devido à inexistência de departamentos e gerência específica de RS, as mulheres enfrentam dificuldade para desenvolver a RS nas organizações. Assim a maioria $(93,75 \%)$ das gestoras assegura que para dar continuidade as ações de RS têm necessidade de pedir autorização de um superior para poder dar continuidade ao processo de RS. Apenas 6,25\% nunca precisam pedir autorização de um superior para tomar decisões a respeito da RS. Estes dados comprovam que as organizações ainda não estão totalmente envolvidas com o processo de RS e as gestoras ainda não têm poder de decisão nas organizações em que se inserem. Assim, Bourdieu (1999) afirma que para que as mulheres cheguem a conseguir uma posição maior no mercado de trabalho, elas devem apresentar não só o que é exigido, mas também um conjunto de atributos que os homens freqüentemente atribuem ao cargo, como: estrutura física e aptidões e a autoridade dita natural, alem disso, a segurança, a qual foram preparados e treinados tacitamente enquanto homens.

Assim sendo, verificou-se que $31,25 \%$ das gestoras ainda não conduzem ou não tem pessoas que dependem de sua autorização para executar e desenvolver ações de RS. Entretanto, a maioria 68,75\% das entrevistadas administra uma equipe de trabalho, as quais dependem da autorização da entrevistada para dar continuidade às ações de RS, confirmando que as entrevistadas estão ganhando espaços nas organizações e em meio a grandes hierarquias masculinas, e com isso já conseguem dirigir equipes. De tal modo, Irigaray e Vergara (2009) afirmam que nesse mundo masculino, as mulheres são educadas a participarem do jogo de disputa pelo poder por procuração, isto é, por intermédio dos homens (via casamento) e são sempre alocadas a uma posição exterior e subordinada; elas têm como função primordial cuidar dos jogadores: os homens.

Como o poder de decisão das gestoras é limitado para o desenvolvimento da RS, elas dependem da autorização de um superior para tomar decisões de RS, que muitas vezes não esta ligada ao processo. A maioria (56,25\%) afirma que "às vezes" tem suas decisões aprovadas, pois muitas vezes o superior não tem a mesma visão e acaba não autorizando a execução de suas idéias; $25 \%$ têm suas decisões aprovadas sempre pelo superior, o que demonstra que, apesar de ser um valor relativamente baixo, as organizações já estão se adaptando ao processo de RS; $12,5 \%$ não responderam a questão e, 6,25\% não sabem a freqüência que o superior autoriza a execução das suas decisões para a RS. Evidenciando assim que algumas das gestoras ainda não têm voz ativa dentro da organização e não tem conhecimento de como ocorre às decisões da organização para que seja executada alguma atividade, e conseqüentemente não têm acesso aos resultados da RS. Entretanto, verifica-se que a grande maioria $81,25 \%$ das gestoras afirma que não se sentem menosprezadas, por ser mulher, com relação ao poder de decisão dentro das organizações, demonstrando que as mulheres estão conquistando espaços no mercado de trabalho. Entretanto, 18,75\% das entrevistadas se sentem um pouco diminuídas no poder de decisão por ser mulher. Estes dados indicam, portanto, que as mulheres não se sentem diminuídas ou inferiores em relação aos homens no poder de decisão dentro das organizações.

Com relação à formação da equipe de RS, em 9 empresas os grupos são mistos com homens e mulheres, em 3 a equipe é composta por somente mulheres, 4 entrevistadas não responderam essa questão. Nesse contexto, conforme $68,75 \%$ das entrevistadas não têm preferência entre trabalhar com homens ou com mulheres, indicando que as entrevistadas acreditam que para desenvolver a RS nas organizações é necessário o envolvimento de ambos os gêneros, ambos lutando pelo mesmo resultado: o bem-estar de todos. Entretanto, 18,75\% afirmam ter mais facilidade de trabalhar com mulheres nas 
questões sociais; em igual percentual $(6,25 \%)$ as entrevistadas não preferem trabalhar com mulheres e não responderam à questão.

Em relação ao desenvolvimento da RS pelas gestoras observa-se que são utilizadas estratégias nas organizações para que o processo de RS ocorra. Assim para $68,75 \%$ das organizações a RS esta inserida no desenvolvimento de projetos e programas; $37,5 \%$ ocorrem na motivação e integração das equipes dentro da organização; em igual percentual (18,75\%) a RS é centralizada em apenas um setor na organização, é voltada para a preocupação com a qualidade dos produtos e as entrevistadas apresentam outros meios onde é percebida a RS nas estratégias, sendo eles: ações desenvolvidas, principalmente, pelo RH e pelo marketing da organização e a geração de renda através do reaproveitamento de materiais; $12,50 \%$ afirmam que a RS é incorporada em toda a organização; $6,25 \%$ acreditam que a RS não é prioridade, é vista apenas como projeto, indicando que a RS ocorre nas organizações pesquisadas, mas não engloba toda a organização, apenas concentra-se em um setor ou departamento. Apesar das gestoras apontarem estes fatores como estratégias para o desenvolvimento da RS, ainda não apresentam estratégias bem definidas e formais designadas somente ao desenvolvimento da RS.

Embora a RS não se encontre inserida formalmente nas estratégias das organizações, já é possível notar a preocupação das organizações em minimizar as demandas sociais, pois $50 \%$ afirmam que a RS já ocorre através do relacionamento com o público interno e externo. Ullrich (2009) ressalta que é preciso expressar, formalmente, que a empresa adota procedimentos voltados para a valorização de minorias, e uma cultura empresarial que incorpore práticas éticas, preocupações com a comunidade de entorno, entre outras. Esta é uma preocupação que faz parte do processo de mudanças internas, geradas pela RS. Porém, já se percebe que 37,50\% das organizações adotam a RS para que haja reconhecimento dos stakeholders, demonstrando que as organizações passaram a se preocupar com todos os públicos que se relacionam com ela; em igual percentual $(31,25 \%)$ adotam a RS como marketing e na minimização dos impactos; além disso, na mesma porcentagem (25\%) as entrevistadas afirmam que as organizações adotam a RS para se manter competitivas no mercado e outros fins, como: a formação de redes de cooperação, focada para a sustentabilidade do negócio, o desenvolvimento de projetos e a essencialidade da RS para o negócio da empresa. Ainda no mesmo percentual de $(12,5 \%)$ adotam a RS para a redução de impostos, principalmente o imposto de renda e também voltada para a filantropia e o assistencialismo.

Observou-se ainda que nenhuma gestora define a adoção da RS pela organização como voltada para a geração de lucro, como pressão da sociedade e cobrança legal/trabalhista. Demonstrando que as organizações já apresentam alguma preocupação acerca do processo de RS. Todavia, Ullrich (2009) ressalta que não há uma cultura nas organizações em que a RS seja prioritária, deste modo, está nas mãos das gestoras de RS implantar este desafio, alem de que as organizações possuem limites em sua atuação na área social, e o principal papel das organizações é o econômico.

No entanto, as gestoras apresentam várias dificuldades que influenciam no processo de desenvolvimento da RS no qual atuam. Dentre muitas, encontram-se a captação de recursos (indicando que as organizações encontram-se ainda em fase de amadurecimento quanto ao processo de RS, disponibilizando poucos recursos para o desenvolvimento da RS na organização), a falta de comunicação (pois é através da comunicação, que os gestores planejam e direcionam os recursos para desenvolver as atividades da organização), a questão da cultura organizacional (indicando que as organizações encontram-se em diferentes níveis quanto ao processo de RS), alem destes problemas, o maior apresentado pelas gestoras é a questão financeira, pois as organizações não estão estruturadas para desenvolver a RS como um todo, não disponibilizando recursos suficientes para o processo de RS.

Deste modo, se percebe que estes fatos influenciam na participação das mulheres no desenvolvimento da RS, pois as gestoras ainda não detêm o poder de decisão dentro das organizações, tendo necessidade de pedir autorização para seus superiores que muitas vezes não autorizam suas decisões, impedindo o real desenvolvimento da RS e dos projetos que fomentariam estas ações. Por isso, que as gestoras asseguram que a captação de recurso financeiro é a dificuldade maior para elas como 
gestoras de RS. Porém, verificou-se que as gestoras não têm dificuldades quando necessitam de apoio da gestão superior para desenvolver a RS na organização, mesmo afirmando que às vezes não tem suas decisões aceitas. Verifica-se certa contradição entre as respostas das gestoras e a atual situação de desenvolvimento da RS, pois de um lado se encontra a dificuldade na captação de recursos e a falta de comunicação na organização e de outro se encontra o apoio da gestão superior no desenvolvimento dos projetos de RS. Deste modo, entende-se que as gestoras desenvolvem a RS de acordo com os objetivos da gestão superior e do rumo que desejam que a organização siga, tornando o processo de RS mais lento, afinal as decisões são tomadas pela gestão superior.

Entretanto, fatores como a gestão muito machista e a falta de apoio dos setores da organização, não foram mencionados pelas gestoras como dificuldades na gestão da RS. Observa-se que as entrevistadas não apresentam problemas com esta questão não reconhecem atitudes masculinas que interfiram na relação social. Neste sentido, Irigaray e Vergara (2009) ressaltam que o comportamento masculino em relação às mulheres é na maioria das vezes travestida em falas que, aparentemente, são politicamente corretas ou ocultadas sob a máscara de humor, fazendo com que as mulheres não liguem para tais atitudes, desconsiderando-as.

Contudo, ainda que as gestoras não possam tomar decisões acerca do processo de RS, as mesmas apresentam motivos específicos que as levam a atuarem com RS. Quando solicitado para que as gestoras descrevessem uma nota ( 0 a 10) para os motivos que as leva a desenvolverem a RS nas organizações, constatou-se que as notas mais elevadas ( 9 a 10) foram para a sintonia das gestoras com essa temática; comprometimento com a questão social pelo perfil histórico no envolvimento com a família; interação com as pessoas e afetividade. Este resultado coincide com o próprio perfil das mulheres que são consideradas mais sensíveis quanto à participação e dedicação nas problemáticas sociais. O homem por sua vez é visto como mais racional assim Bourdieu (1999) afirma que para os homens é destinada a vida pública, do direito e a realização de atos breves e perigosos, já as mulheres ficam com os trabalhos privados e escondidos, ou seja, os trabalhos domésticos e o com o cuidado dos filhos, que são os serviços sociais ou então educativos, deste modo, a sociedade determina o estatuto social em que as mulheres se encontram inseridas.

Neste contexto, salienta-se que as mulheres apesar das várias conquistas que obtiveram nos últimos anos, principalmente pelo acesso que lhes foi permitido a sociedade, ainda é possível notar que as mulheres gestoras sofrem com a discriminação entre gêneros, na pesquisa 75\% delas afirma que este é um fator que limita a gestão da mulher dentro da organização; as outras (25\%) não responderam esta questão. Estes dados demonstram que as mulheres ainda sofrem com discriminações nas organizações, e conseqüentemente na sociedade, que pode estar relacionado com o fato de ocuparem cargos mais altos, o que gera certo receio entre as pessoas, pois não estão habituados com esta realidade, já que a mulher ate o momento, não ocupava cargos de representatividade na sociedade. Neste sentido, Irigaray e Vergara (1999) ressaltam que o comportamento masculino em relação às mulheres é na maioria das vezes travestida em falas que, na aparência, são politicamente corretas, proferidas suavemente, ou escondida sob a máscara de humor, fazendo com que as mulheres não liguem para tais atitudes, desconsiderando-as, outro problema é no desenvolvimento de projetos e programas.

Entretanto, observou-se na que a maioria (93,75\%) das gestoras recebe apoio da família para que mantenha sua carreira profissional. Deste modo, observa-se que as mulheres estão conquistando espaços e também a compreensão de suas famílias (marido e filhos) em relação às novas atividades que passaram a desenvolver e a nova estrutura familiar que estão compondo, onde homens e mulheres trabalham na vida pública e muitas vezes dividem as tarefas domésticas. Em contrapartida, observa-se que 6,25\% raramente têm apoio da família em relação ao seu trabalho, confirmando que a mulher ainda precisa conquistar espaços no mercado de trabalho 
Tabela 2: Dificuldades das gestoras em conciliar trabalho/família

\begin{tabular}{l|c|c}
\hline $\begin{array}{c}\text { DIFICULDADES PARA CONCILIAR TRABALHO } \\
\text { COM FAMÍLIA }\end{array}$ & FREQÜENCIA & $\%$ \\
\hline Filhos & 3 & 18,75 \\
\hline Organização da casa & 3 & 18,75 \\
\hline Remuneração alta & 0 & 0,00 \\
\hline Relação conjugal & 1 & 3,25 \\
\hline Remuneração baixa & 5 & 43,25 \\
\hline Horários & 7 & 93,75 \\
\hline Excesso de compromisso & 15 & 0,00 \\
\hline Outros & 0 & $\mathbf{1 0 0 , 0 0 \%}$ \\
\hline TOTAL & $\mathbf{1 6}$ & \\
\hline
\end{tabular}

Fonte: Dados da pesquisa

Embora o apoio recebido da família seja fundamental, verifica-se na Tabela 2, numa questão de múltipla escolha que $93,75 \%$ das gestoras afirmam que o excesso de compromisso é a principal dificuldade em conciliar família e trabalho. Estes fatores são observados no contexto feminino que ainda assume as duas funções - família e emprego resultando em dupla jornada e muita cobrança, seguida pelo horário em $43,75 \%$ e remuneração baixa em $31,25 \%$. Uma surpresa foi à baixa preocupação em índice igual de (18,75\%) com os filhos e a organização da casa, caso que muitas vezes é visto como central em várias discussões. Este resultado chama a atenção pelo fato de que as gestoras afirmam que atuam com responsabilidade social por causa da afinidade e sintonia com a temática, pois podem expressar seus sentimentos no cuidado com outras pessoas. No entanto, observa-se que as gestoras não apresentam preocupação com os filhos e com a organização da própria casa, talvez porque a maioria delas encontra-se ainda em fase de formação familiar e são jovens que mesmo em idade fértil ainda não almejam ter filhos, assim destinam estes sentimento "maternos" através da profissão.

Uma questão pouco indicada $(6,25 \%)$ foi à relação conjugal, que pode relacionar-se a mudança de comportamento quanto à atual busca pela independência da mulher. Assim, percebe-se que as mulheres entrevistadas apresentam dados semelhantes aos comparados com a história das mulheres, esses fatos são observados pelos anos de luta e dedicação para a conquista de espaços na sociedade que a mulher busca, assim sendo, se observa mudanças significativas nesta história. Percebe-se que as entrevistadas não buscam somente o casamento, como era obrigadas a fazer antigamente, e também a constituição de uma família, o cuidado com os filhos e o marido, hoje em dia, as mulheres procuram dar prioridades à busca pela identidade pessoal, ter independência, além da realização de seus sonhos, subentende-se assim que a mulher adia o casamento para que tenha ascensão profissional.

Conforme Bourdieu (1999) as mulheres apesar de estarem objetivadas nos cargos e nas carreiras, atuam através de três princípios práticos: o primeiro é o prolongamento das funções domésticas; segundo que uma mulher não pode ter autoridade sobre os homens encontrando-se relegada a funções subordinadas; por último confere ao homem o monopólio da manutenção dos objetos técnicos. Observa-se que as mulheres mesmo tendo ascensão profissional acabam "pagando" pelo insucesso doméstico (casamento, filhos entre outras dificuldades), alem de continuar subordinada ao marido que espera que ela pelo menos faça metade de suas tarefas domésticas. 0 resultado destes processos é a dupla jornada de trabalho - a preocupação com o trabalho e com a família, seguido do excesso de compromissos. Nenhuma gestora acredita que a remuneração alta e outros fatores quaisquer sejam dificuldades para conciliar trabalho e família. 0 item remuneração alta poderia ter sido um fator de dificuldade caso as gestoras tivessem salários superiores ao de seus parceiros, gerando conflitos na relação conjugal, mas isso ainda não é observado na sociedade, pois as mulheres continuam inseridas no mercado em menor número e ganhando menos do que os homens mesmo desenvolvendo as mesmas atividades (ODM, 2010).

Deste modo, quando a mulher encontra-se inserida no mercado de trabalho apresenta um avanço no combate que travou há muitos anos, entretanto ainda é preciso pelo poder de decisão que ainda é 
limitado para as mulheres perante os homens. Para que a mulher se mantenha no mercado de trabalho é preciso modificar algumas coisas em relação ao papel da mulher, como: a diminuição do número de filhos e a organização da casa que devido ao excesso de compromissos acaba não sendo prioridade. Entretanto, no desenvolvimento da RS o sentimento materno e a afinidade com a temática de RS continuam sendo os motivos para que as mulheres desenvolvam esta atividade nas organizações do município.

Por fim, é possível notar que as entrevistadas procuram estratégias para que o processo de RS ocorra nas organizações, uma dessas são os encontros mensais que mantêm através do Núcleo de RS/ ACIB, pois conseguem extrair idéias e também se motivarem para dar continuidade às ações. As entrevistadas utilizam os encontros para que juntas mantenham instrumentos de cooperação como a formação de uma "rede social", em que buscam manter contatos entre si e possam apresentar a atual realidade das organizações de Blumenau em relação ao processo de RS, amadurecendo dessa maneira o processo de RS nas organizações em que se encontram inseridas. Diante desse desafio, algumas estratégias podem ser adotadas pelas gestoras no sentido de agilizar o processo de construção e desenvolvimento da RS, entre elas: a) políticas de aproximação dos setores da organização em prol da RS, conquistar o apoio dos gestores e os colaboradores de um modo mais amplo vislumbrando ações conjuntas; b) divulgação e socialização das ações para valorizar as conquistas e minimizar os problemas relativos à confiabilidade e adesão do processo de RS; c) indicar um projeto específico para diminuir as desigualdades entre gêneros, disseminando os limites e desafios na participação de todos na organização; d) desenvolver projetos e atividades junto com organizações públicas (Estado) e também em escolas, que são os reprodutores de toda a ordem social, demonstrando que homens e mulheres precisam ser tratados com igualdade, e assim contribuir para a diminuição da dominação masculina.

\section{CONCLUSÃO}

Nesse estudo pode-se observar que a participação das mulheres na condução da responsabilidade social é bastante significativa, das 24 organizações vinculadas ao Núcleo de RS/ ACIB, 21 delas são representadas por mulheres. Este interesse das mulheres pelas questões sociais é verificado na identificação delas em relação à temática social. Conforme o processo histórico, a mulher que assumiu por muito tempo, o papel de cuidar da casa e da família, apresentando maior facilidade em desenvolver atividades profissionais, onde pode expressar seu sentimento de afetividade e de cuidado com as pessoas.

Este fato foi observado na grande satisfação e envolvimento pessoal que elas afirmam possuir com a gestão da responsabilidade social nas organizações que atuam. Porém, como ainda aliam em muitos casos a função doméstica com a profissional, todas afirmaram que atualmente sofrem muita pressão e cobrança resultante do excesso de atividades. Este fator é visto como um empecilho pessoal que compromete seu desempenho perante seus superiores na hierarquia organizacional. Ressaltando que as gestoras entrevistadas são dirigidas apenas por homens, todavia garantem não haver discriminação entre gêneros. Entretanto, as gestoras enfrentam alguns problemas em relação à história cultural (machista) que descreve o papel principal da mulher na sociedade o de ser mãe e dona-de-casa e não uma profissional qualificada, deste modo, mesmo que as mulheres tenham uma boa formação acadêmica enfrentam dificuldades para se inserirem em cargos mais elevados, além disso, as gestoras afirmam que as políticas de ascensão dentro da organização ainda são fatores limitadores.

Apesar destas dificuldades, as gestoras podem contar com um atributo essencial na mudança de visão da sociedade para com a inserção da mulher na vida pública, que é o apoio das suas famílias para se manter em atividade na sociedade, evidenciando que as mulheres já conquistaram a confiança das pessoas que as cercam e demonstra que apesar de terem assumido uma carreira profissional são capazes de se comprometer com ambas as atividades. Além disso, este apoio demonstra que os homens (pais e maridos) estão construindo uma sociedade diferente, onde homens e mulheres são iguais. No processo de desenvolvimento dos projetos de responsabilidade social, embora já demonstrando uma evolução no contexto organizacional que é considerado embrionário na maioria 
dos casos, as gestoras encontram algumas barreiras relativas ao modo de estruturação desse processo, que ainda não é visto como prioridade nas organizações estudadas. Este cenário dificulta a atuação das gestoras, uma vez que não possuem gerência de decisão na criação de políticas em nível estratégico, dependem muito de autorização da alta gestão para efetivar suas ações.

Nesta pesquisa foi verificado que as mulheres entrevistadas não apresentam estratégias específicas e bem definidas para o desenvolvimento da RS nas organizações onde o processo ocorre, além disso, o apoio proveniente da gestão superior não é suficiente para que a RS englobe todos os setores e departamentos da organização. Por fim, homens e mulheres precisam ainda trabalhar muito esta questão da inserção da mulher no mercado de trabalho e consequentemente, poderem ocupar cargos em níveis superiores, não sendo limitada pela cultura ou políticas organizacionais.

Conclui-se, assim, que esta discussão não termina com estes resultados, uma vez que, este estudo remete a necessidade de novos olhares sobre esta temática tão complexa. Não se pretendeu exaurir as reflexões, pois acredita-se que é fundamental que novas pesquisas sejam realizadas para aprofundar os diálogos que versam sobre a participação da mulher na gestão e no desenvolvimento da RS.

\section{REFERÊNCIAS}

ALVES, Elvisnney Aparecido. Dimensões da responsabilidade social da empresa: uma abordagem desenvolvida a partir da visão de Bowen. Revista de Administração, São Paulo, v.38, n.1, p.37-45, jan./fev./mar. 2003.

ASHLEY, Patrícia Almeida. Ética e RS nos negócios. São Paulo: Saraiva, 2003.

ASSIS, Karina Gomes de; BELEM, Marcela Purini. Modelos de empresa, modelos de RS. In: XXIX ENEGEP - Encontro Nacional de Engenharia de Produção, 2009, Salvador: UFBA. Anais... Salvador: UFBA, 2009.

BARSTED, Leila de Andrade Linhares. A revisão da modernidade a partir do olhar crítico da mulher. In: BRANDÃO, Margarida Luiza Ribeiro; BINGEMER, Maria Clara L. (Org.). Mulher e relações de gênero. São Paulo: Loyola, 1994.

BEAUVOIR, Simone de. 0 segundo sexo. Rio de Janeiro: Nova Fronteira, 1980.

BOURDIEU, Pierre. A dominação masculina. Rio de Janeiro: Bertrand Brasil, 1999.

BOWEN, Howard Rothmann. Responsabilidades sociais do homem de negócios. Rio de Janeiro: Civilização Brasileira, 1957.

BRANDÃO, Margarida Luiza Ribeiro; BINGEMER, Maria Clara L. (Org.). Mulher e relações de gênero. São Paulo: Loyola, 1994.

CABRAL, Nara Grivot. RS: relacionando atitudes e valores. In: ARAÚJO, Margarete Panerai; BAUER, Maristela Mercedes. Desenvolvimento Regional e RS: construindo e consolidando valores. Novo Hamburgo: Feevale, 2005.

CALÁS, Marta B.; SMIRCICH, Linda. Do ponto de vista da mulher: abordagens feministas em estudos organizacionais. In: CLEGG, Stewart R.; HARDY, Cynthia; NORD, Walter R. Handbook de estudos organizacionais: modelos de análise e novas questões em estudos organizacionais. São Paulo: Atlas, 1998. Tradução de: Miguel Caldas, Roberto Fachin e Tânia Fischer.

CARNEGIE CORPORATION. About Carnegie Corporation. Disponível em: <http://carnegie.org/about-us/foundation-history/about-andrew-carnegie/>. Acesso em: 16 nov. 2009.

CARROLL, Archie B. The pyramid of corporate social responsibility: toward the moral management of organizacional stakeholders. Business Horizons. v. 34, n. 4, p. 39-46, Jul./Aug. 1991.

CAPPELLIN, Paola; GIFFONI, Raquel. As empresas em sociedades contemporâneas: a responsabilidade 
social no Norte e no Sul. Caderno CRH, Salvador, v. 20, n. 51, p. 419-434, Set./Dez. 2007.

CHAUÍ, Marilena. Convite à filosofia. São Paulo: Ática, 2000.

DREHER, Marialva Tomio. Gestão social, sustentabilidade e desenvolvimento. Projeto de pesquisa. Blumenau, 2009.

FOURNIER, Valérie; SMITH, Warren. Scripting Masculinity. Ephemera: theory \& politics in organization. V. 6, n. 2, p. 141-162, 2006. Dísponivel em: <www.ephemeraweb.org>. Acesso em: 27 jun. 2010.

FRIEDMAN, Milton. Capitalismo e liberdade. 3. ed. São Paulo: Nova Cultural, 1988.

GIL, Antonio Carlos. Métodos e técnicas de pesquisa social. 5. ed. São Paulo: Atlas, 1999.

IRIGARAY, Hélio Arthur Reis; VERGARA, Sylvia Constant. Mulheres no ambiente de trabalho: abrindo o pacote "gênero". In: XXXIII EnANPAD, 2009, São Paulo. Anais... São Paulo: ANPAD, 2009.

INSTITUTO ETHOS. Sobre o Instituto Ethos. Disponível em: <http://www.ethos.org.br>. Acesso em: 10 dez. 2009.

PERROT, Michelle. Mulheres públicas. São Paulo: UNESP, 1998. (Primas).

RUFFEIL, Saphyra. RS de empresas é fazer bem feito. ADVB - Associação dos Dirigentes de Vendas e Marketing do Brasil, Pará, 17 nov. 2009. Disponível em: <http://www.advbpa.com.br/artigosart_det.asp?id=9> . Acesso em: 17 nov. 2009.

SARDENBERG, Cecília M.B.; COSTA, Ana Alice A.. Feminismos, feministas e movimentos sociais. In: BRANDÃO, Margarida Luiza Ribeiro; BINGEMER, Maria Clara L. (Org.). Mulher e relações de gênero. São Paulo: Loyola, 1994.

SCOTT, John. 50 sociólogos fundamentais. São Paulo: Contexto, 2007.

STONER, James Arthur Finch; FREEMAN, R. Edward. Administração. 5. ed. Rio de Janeiro: PrenticeHall, 1985. p.72-73.

ODM. Acompanhamento municipal dos Objetivos de Desenvolvimento do Milênio. Disponível em: <http://www.portalodm.com.br/>. Acesso em: 28 jul. 2010.

ULLRICH, Danielle Regina. Responsabilidade social e desenvolvimento local: uma leitura da cooperação intersetorial em Blumenau (SC), enfocando os movimentos das organizações do Núcleo RS/ACIB. 2009. Dissertação (Mestrado em Desenvolvimento Regional) - PPGDR, CCHC, Universidade Regional de Blumenau, Blumenau, 2009. 